\title{
The Visual Field in Chronic Simple Glaucoma and Ocular Hypertension; Its Character, Progress, Relationship to the Level of Intraocular Pressure and Response to Treatment
}

\author{
R. P. CRICK, ${ }^{*}$ R. VOGEL,$\dagger$ R. B. NEWSON, $\ddagger$ M. J. SHIPLEY, $\ddagger$ H. BLACKMORE, ${ }^{*}$ \\ A. PALMER,$\S$ and C. J. BULPITT $\S$
}

London and Pennsylvania

\begin{abstract}
Summary
Nine hundred and twenty-nine patients with chronic simple glaucoma or ocular hypertension were followed for one to thirteen years using the King's College Hospital glaucoma data base.

The $30^{\circ}$ visual field was divided into twelve clinical zones. The field sensitivity and its change as measured by the mean differential threshold both in these zones and overall was followed to determine the pattern and progress of field loss in eyes diagnosed initially as chronic simple glaucoma or ocular hypertension.

The findings were related to other similar analyses in which the mean differential threshold in chronic glaucoma was found to correlate significantly with the initial intraocular pressure and its progress with the mean follow-up intraocular pressure under treatment. Inferences were drawn regarding the nature of chronic simple glaucoma and ocular hypertension and their management.
\end{abstract}

This paper considers the pattern and progress of the visual field loss of patients initially diagnosed as chronic simple glaucoma or ocular hypertension and who were recorded in the King's College Hospital glaucoma data base.

The results are then related to those of our other analyses, on the relationship of the level of the untreated intraocular pressure to initial visual field loss and the level of treated intra- ocular pressure to visual field progress. ${ }^{1}$ Comments on the nature of chronic simple glaucoma and ocular hypertension and their management are made.

\section{Method}

The intraocular pressure was measured using the Goldmann applanation tonometer (HaagStreit, Bern) and the visual fields assessed by

*Eye Department, King's College Hospital, London.

†M.S.D. Research Laboratories, West Point, P.A., U.S.A.

$\ddagger$ Department of Epidemiology, London School of Hygiene and Tropical Medicine, London.

$\S$ Division of Geriatrics, Royal Postgraduate Medical School, London.

Supported by King's College Hospital Research Committee, International Glaucoma Association and M.S.D. Chibret.

Correspondence to: R. P. Crick, Eye Department, King's College Hospital, Denmark Hill, London SE5 9RS, England. 
the Friedmann Visual Field Analyser (Clement Clarke, London) in which the $30^{\circ}$ visual field was divided into quadrants and each quadrant was further divided into three zones which from the fixation point were $0-10^{\circ}$, $10-20^{\circ}$ and $20-30^{\circ}$, containing two, four and three, stimulus loci respectively². Units of four decibels were employed which both shortened the test to avoid patient fatigue and involved only single numbers for the ready calculation of mean threshold sensitivity. The threshold sensitivities of all the points tested in each zone were averaged to give a mean zonal value (Fig. 1). The display of mean zonal threshold sensitivities was in the form of a 'field cross', as shown, and an average threshold value for the whole $30^{\circ}$ field could also be simply calculated. This method shows at a glance in single numbers the mean sensitivity of 12 clinically useful zones of the field and a mean value for the field as a whole. The method was devised for computer storage and has been used at King's College Hospital for over twenty years. It has been found invaluable for field comparisons over a long period. The method is of general application and has been equally useful for long term visual field surveillance using the Octopus perimeter.

In this paper some of the threshold values have been converted to decibel units for comparison with existing literature.

An analysis of the presenting and final threshold sensitivity of the 12 zones was carried out both in eyes with ocular hypertension and chronic simple glaucoma. It was considered that analysis of the progress of static threshold values would give more information and have advantages in interpretation compared with the method of finding the frequency distribution of defect to one particular stimulus which has sometimes been used in previous visual field studies of this type. ${ }^{3,4}$

Eyes in the Study (Tables I and II)

The study included 542 right eyes and 527 left eyes with chronic simple glaucoma followed

\section{K.C.H. COMPUTERISED DATA BASE METHOD OF VISUAL FIELD REPRESENTATION (APPLIED TO FRIEDMANN ANALYSER)}
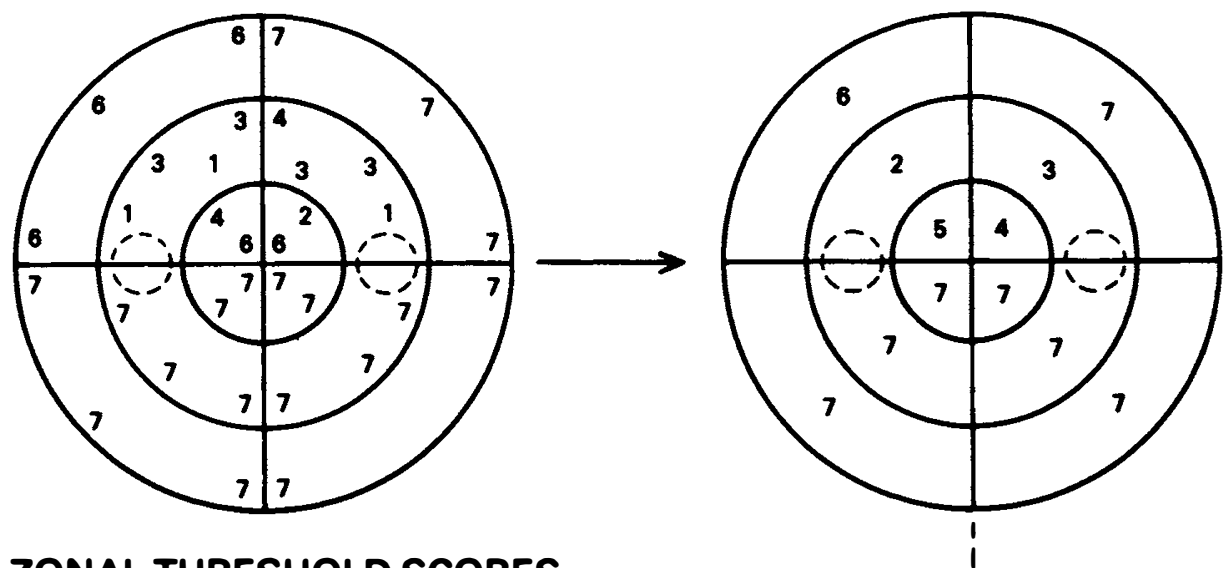

THE ZONAL THRESHOLD SCORES ARE RECORDED AS A 'FIELD CROSS' UNITS ARE $(4 \mathrm{~dB}+1)$

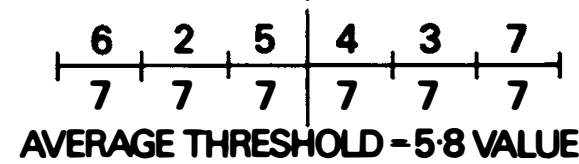

\section{EACH QUADRANT OF THE FIELD IS DIVIDED INTO 3 ZONES INNER $0^{\circ}-10^{\circ}$, MIDDLE $10^{\circ}-20^{\circ}$, OUTER $20^{\circ}-30^{\circ}$}

Fig. 1 KCH Computerised Glaucoma Data Base form of visual field representation. (Friedmann visual field analyser) 'Field Cross' method of calculating mean threshold sensitivity of 12 zones and the whole $30^{\circ}$ field. 
Table I Eyes in study

\begin{tabular}{lccc}
\hline & \multicolumn{3}{c}{ Eyes in study } \\
\cline { 2 - 4 } & R. eyes & L. eyes & Total eyes \\
\hline C.S.G. & 542 & 527 & 1069 \\
O.H. & 183 & 198 & 381 \\
C.S.G. or O.H. & 725 & 725 & 1450 \\
\hline
\end{tabular}

Table II Duration of study

\begin{tabular}{lccccc}
\hline & \multicolumn{4}{c}{ Duration of study } \\
\cline { 2 - 3 } & \multicolumn{2}{c}{ Mean (years) } & & Maximum (years) \\
\cline { 2 - 3 } \cline { 5 - 6 } & R. eyes & L. eyes & & R. eyes & L. eyes \\
\hline C.S.G. & 4.9 & 5.0 & & 12.9 & 12.9 \\
O.H. & 4.0 & 4.0 & & 13.4 & 13.4 \\
\hline
\end{tabular}

for a mean of 5.0 years (maximum 12.9 years) and 183 right eyes and 198 left eyes with ocular hypertension followed for a mean period of 4.0 years (maximum 13.4 years).

Diagnostic Criteria

The 381 eyes with ocular hypertension were so categorised because they satisfied the criteria of the Ferndale Survey definition for 'confirmed ocular hypertension's and though some did show occasional points of slight depression of field sensitivity these could not on traditional clinical criteria be considered to be glaucomatous.

The 1069 eyes with chronic simple glaucoma satisfied the Ferndale criteria for this diagnosis.

\section{Results}

The initial, final and the change in mean sensitivity for the 12 visual field zones in 542 right eyes of patients with chronic simple glaucoma are shown in Figure 2. Initially, two main areas can be distinguished. The first which has a higher sensitivity $(9.2-10.8 \mathrm{~dB})$ includes the upper inner zones and all the lower zones; the second which is less sensitive (7.1-7.9 $\mathrm{dB}$ ) includes the upper outer and upper middle zones.

Although all the zones had low initial sensitivities compared with those of normal patients of the same age, the change during

\section{CHRONIC SIMPLE GLAUCOMA MEAN FOLLOW UP 4.9 YEARS RIGHT VISUAL FIELDS MEAN THRESHOLD SENSITIVITY (dB) OF 542 EYES}

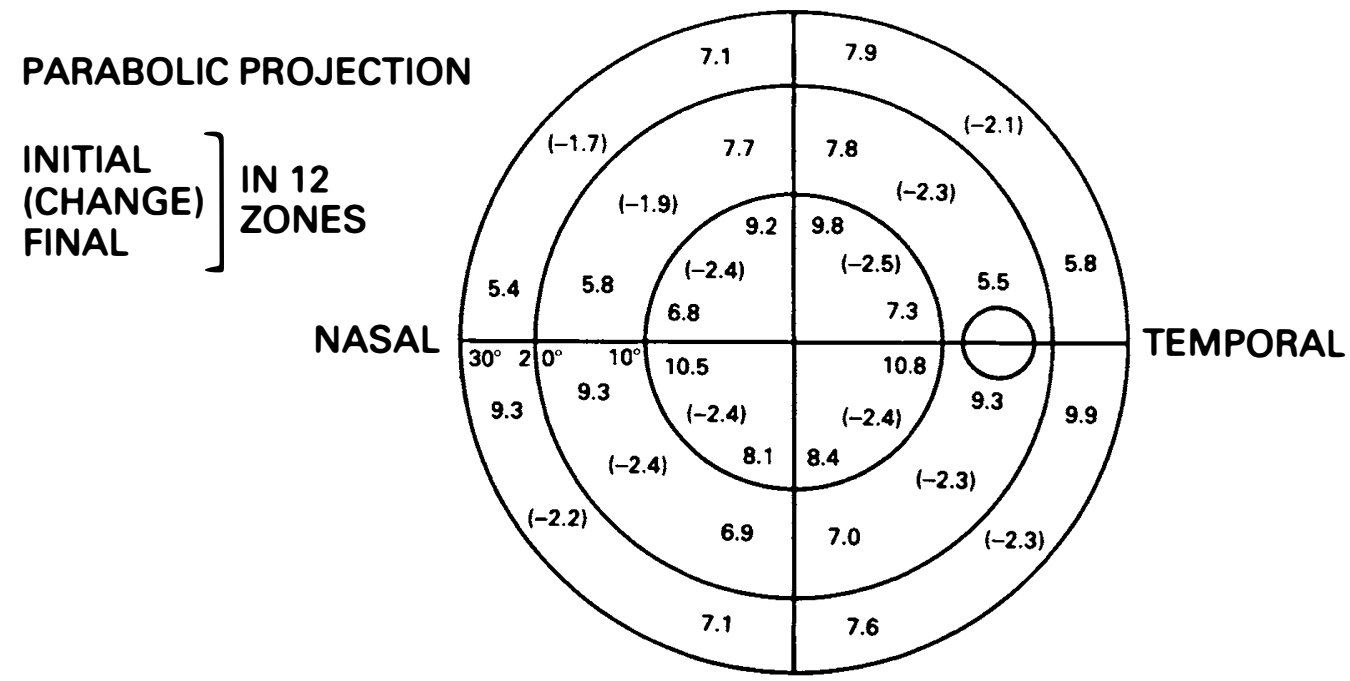

C.S.G. R. EYE

Fig. 2 Chronic simple glaucoma, 542 right eyes. Initial, final and change of mean threshold sensitivity in dB during 5.0 year follow up. 


\section{CHRONIC SIMPLE GLAUCOMA MEAN FOLLOW UP 5.0 YEARS LEFT VISUAL FIELDS (DRAWN AS RIGHT FIELD) MEAN THRESHOLD SENSITIVITY (dB) OF 527 EYES}

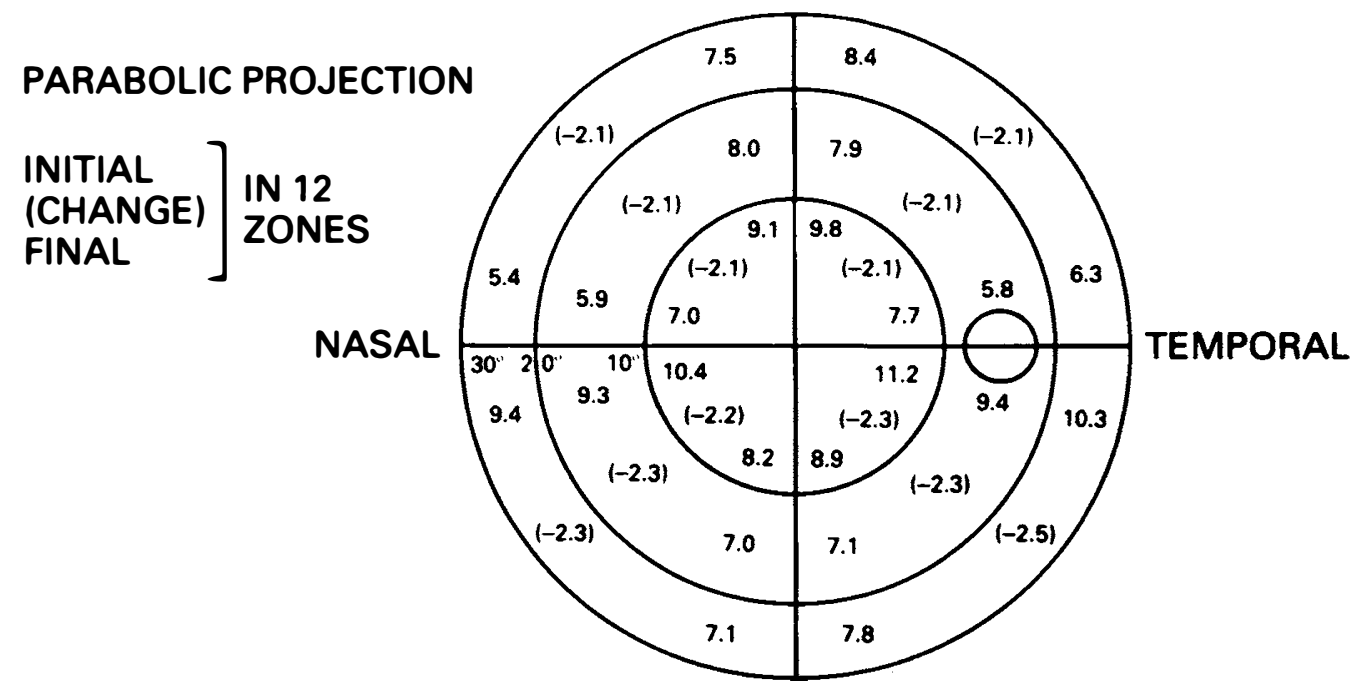

\section{C.S.G. L.EYE (DRAWN AS RIGHT)}

Fig. 3 Chronic simple glaucoma, 527 left eyes. Initial, final and change of mean threshold sensitivity in dB during 5.0 year follow up.

follow up was fairly uniform over the whole field and was greater than the difference in changes between the zones.

The results for 527 left eyes are similar and are shown in Figure 3.

Figure 4 gives the corresponding measurements for 183 right eyes with ocular hypertension. The initial mean sensitivities are, of course, greater than for chronic simple glaucoma but the ranking of zones is the same. The change in mean sensitivity over the period of follow up was also lower than for chronic simple glaucoma.

Figure 5 confirms these results for 198 left eyes with ocular hypertension.

The similarity in ranking of the initial and final sensitivities of the zones is illustrated in Figure 6 for chronic simple glaucoma.

The four zones with low sensitivities are clearly identified.

Figure 7 illustrates the agreement in ranking for the initial sensitivities between chronic simple glaucoma and ocular hypertension eyes and Table III gives the Kendall correlation coefficients between mean sensitivities of eyes with chronic simple glaucoma and ocular hypertension both for initial and final readings. The correlations are reasonably good especially for final readings and the statistical significance is high.

In case lens opacity or retinal degenerative changes may have contributed to the general depression of field sensitivity especially for the inner zones, a subset of 102 right eyes whose final visual acuity was $6 / 6$ or better were similarly analysed as shown in Figure 8.

Although smaller numbers allowed more variable results the central zones did show relatively less deterioration than before, especially the two lower inner zones. Similar results for a corresponding subset of 91 left eyes are shown in Figure 9.

A linear plot of the initial and final thresholds of the subset shows that the ranking of zones is unchanged compared with the whole group.

\section{Discussion}

The data support the view that the difference between ocular hypertension and multifac- 


\section{OCULAR HYPERTENSION MEAN FOLLOW UP 4 YEARS RIGHT VISUAL FIELDS MEAN THRESHOLD SENSITIVITY (dB) OF 183 EYES}

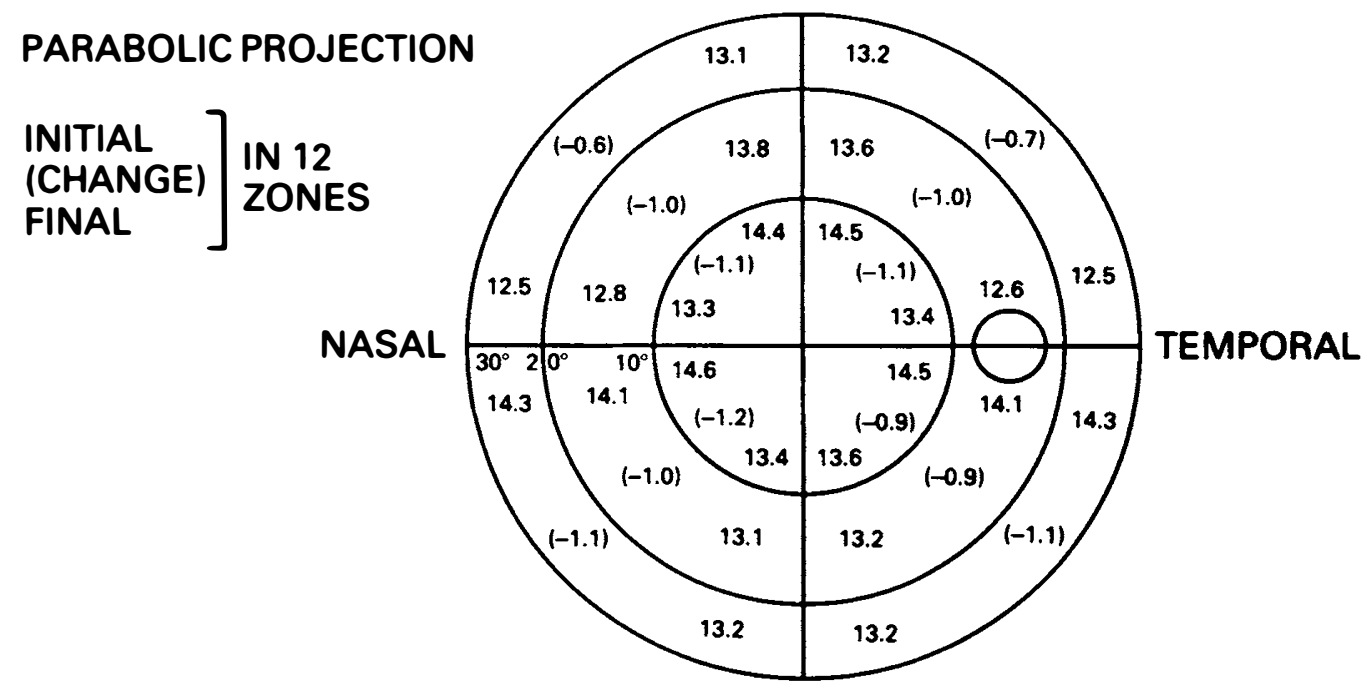

\section{O.H.R.EYE}

Fig. 4 Ocular hypertension, 183 right eyes. Initial, final and change of mean threshold sensitivity in dB during 4.0 year follow up.

torial chronic simple glaucoma is the effect of intraocular pressure relative to the influence of other risk factors for glaucomatous optic atrophy and not the presence of a different specific disease process. They support the concept that chronic simple glaucoma and ocular hypertension are each a part of a Primary Open Angle Glaucoma Complex in which risk factors have contributed in varying proportion to any optic nerve damage which has occurred.

The primary type of low tension glaucoma in which optic nerve damage appears to be predominantly the result of vascular failure in the choroid and the optic nerve head aggravated by the intraocular pressure at whatever level, is the third main element in the complex.

The distribution of normal thresholds has been provided for the Octopus perimeter (Interzeag-Bern) and shows a lower level of sensitivity in the upper half of the field and a gradual reduction of sensitivity from the centre to the periphery which is least in the lower temporal quadrant. The observations of
Bebie on Flammer's normal mean values ${ }^{6}$ indicates that, with age, a decline of sensitivity of about $0.6 \mathrm{~dB}$ per decade over the whole field may be expected. This compares with a rate of loss per decade of $4.4 \mathrm{~dB}$ for chronic simple glaucoma and $2.3 \mathrm{~dB}$ for ocular hypertension in the main study and $1.8 \mathrm{~dB}$ in the subset of eyes with chronic simple glaucoma restricted to those with a final visual acuity of $6 / 6$ or better. The latter probably represents more closely the change specifically due to glaucoma.

The overall reduction of mean sensitivity throughout the field is the striking feature in both chronic simple glaucoma and ocular hypertension and this tends to be greater than the change between different parts of the field which has been so emphasised as a feature of chronic simple glaucoma in the past. It is nevertheless appreciated that in individual cases striking arcuate or temporal wedge depression of the field occurs in chronic simple glaucoma as an expression of nerve fibre bundle damage particularly those appar- 


\section{OCULAR HYPERTENSION MEAN FOLLOW UP 4.0 YEARS \\ LEFT VISUAL FIELDS (DRAWN AS R. FIELD) \\ MEAN THRESHOLD SENSITIVITY (dB) OF 198 EYES}

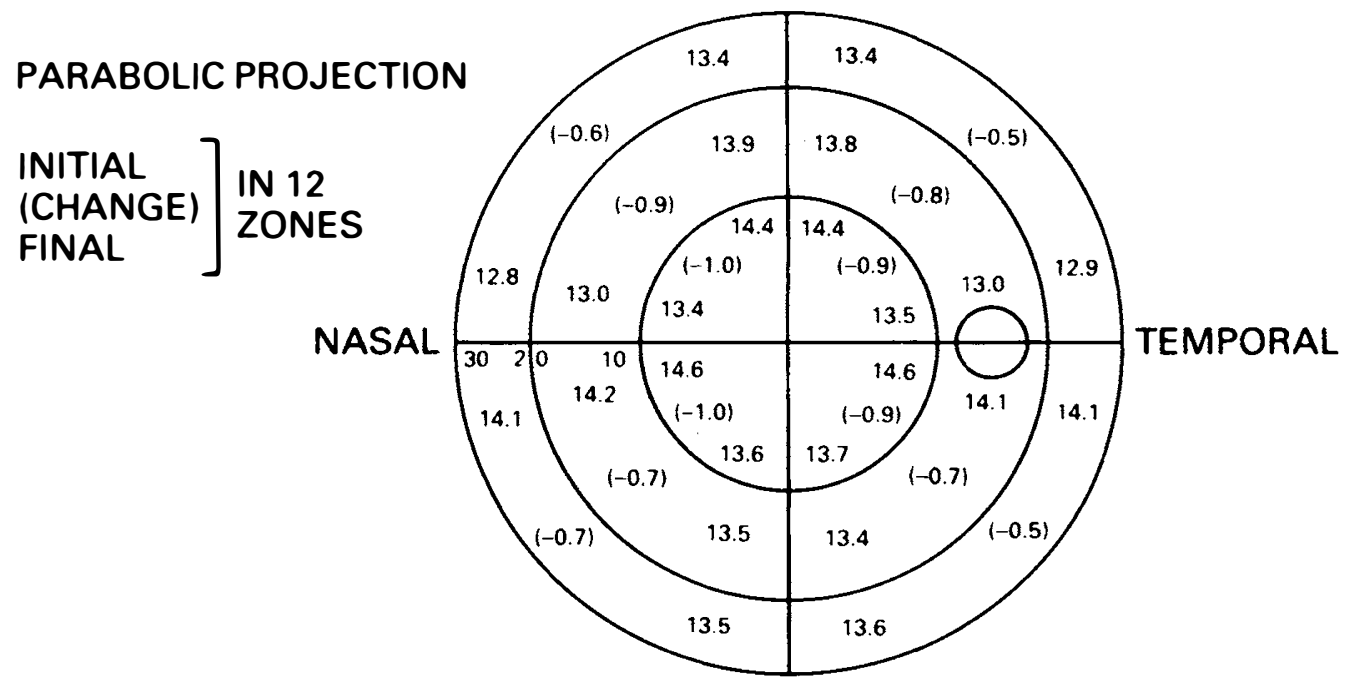

\section{O.H. L.EYE (DRAWN AS RIGHT)}

Fig. 5 Ocular hypertension, 198 left eyes. Initial, final and change of mean threshold sensitivity in $d B$ during 4.0 year follow up.

\section{GRAPH OF C.S.G. INITIAL AND FINAL FIELD THRESHOLDS R.EYES}

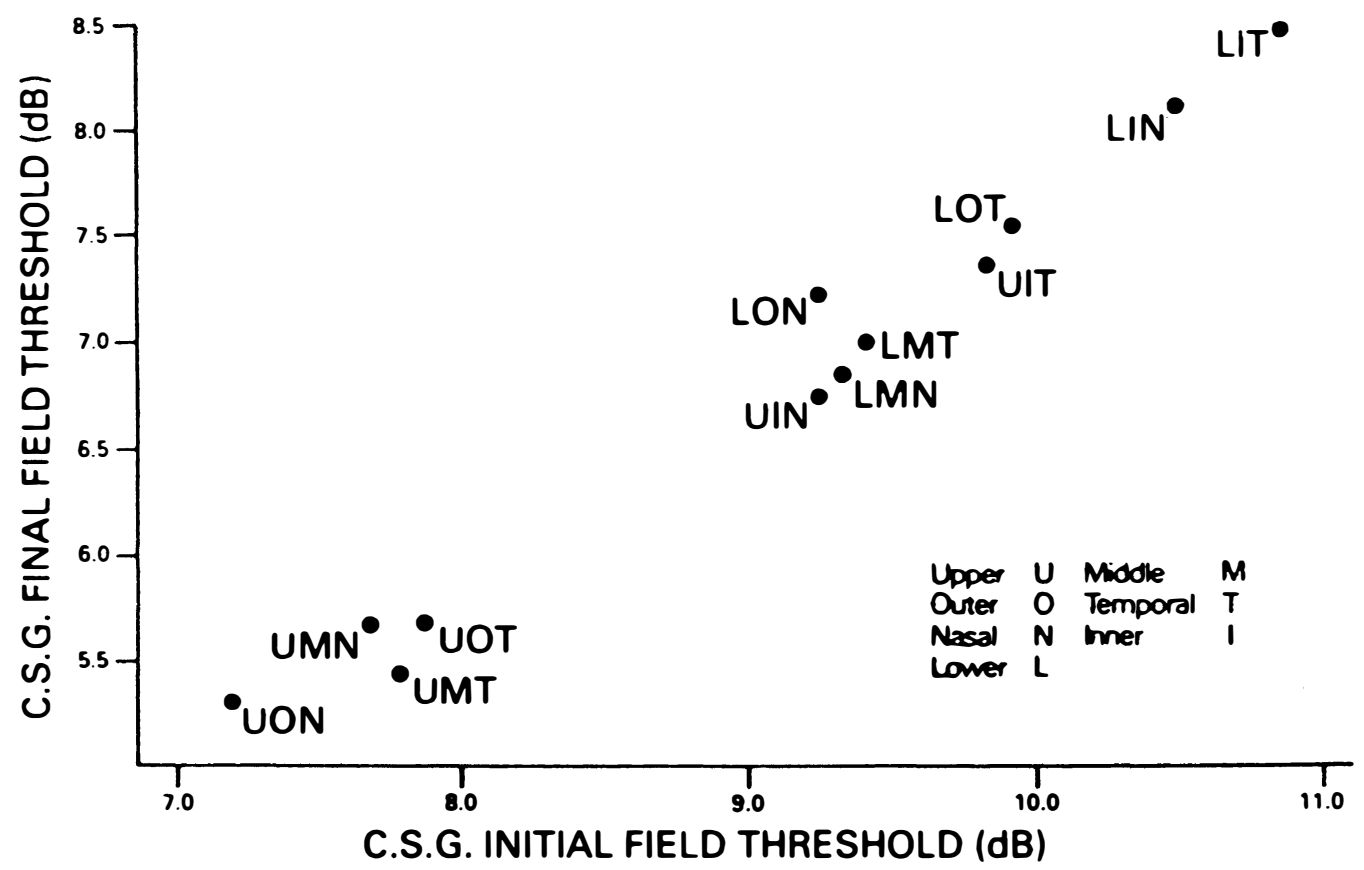

Fig. 6 Chronic simple glaucoma, 542 right eyes, scatter plot of zonal sensitivities in dB showing uniformity of change throughout the visual field. 


\section{GRAPH OF INITIAL FIELD THRESHOLDS IN C.S.G. AND O.H.R. EYES}

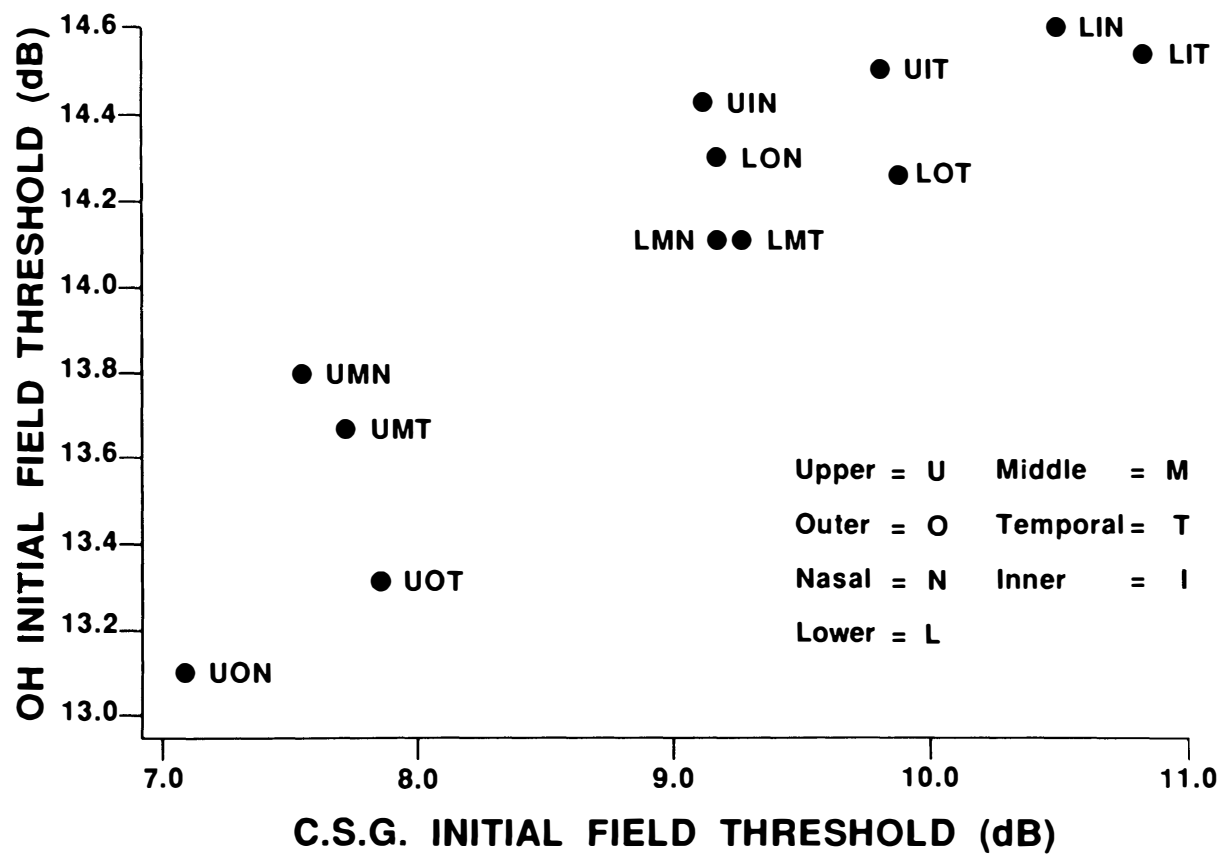

Fig. 7 Scatter plot of zonal sensitivities in $\mathrm{dB}$ for initial visual fields in 542 right eyes with chronic simple glaucoma and 183 right eyes with ocular hypertension showing correlation.

ently more vascularly determined as indicated by splinter haemorrhages on the optic disc.

In the past, however, the adherence of ophthalmologists to kinetic perimetry and the plotting of isopters has led to a misleading emphasis on the importance of arcuate defects and a failure to appreciate that such changes are often small compared with the general loss of sensitivity throughout the field which nevertheless leaves the central field, at and just below fixation as still the most sensitive area, because of its very high threshold sensitivity initially. The role of the intraocular pressure in the genesis of chronic simple glaucoma as well as the value of its reduction by treatment has been denied by some ophthalmologists. ${ }^{7.89}$ The available evidence suggests not only that other factors are operative, but they are even more important than the level of the intraocular pressure. This was indicated by an analysis of the same data base ten years ago. ${ }^{10}$ when a decision curve for the relationship between intraocular pressure and visual field loss (Fig. 10) showed that intraocular pressure was a poor indicator of field loss and that the trade off between sensitivity and specificity was at a cut-off point of $26 \mathrm{~mm} \mathrm{Hg}$. Yet intraocular pressures above $26 \mathrm{~mm} \mathrm{Hg}$ only gave three times the risk of field loss compared with pressures below this level (Risk Ratio 2.8), though there were some significant age and sex variations which require further research. ${ }^{11}$

One of our recent analyses already submit-

Table III Kendall Correlation Coefficients between sensitivity values for 12 zones of the visual field in chronic simple glaucoma and ocular hypertension

\begin{tabular}{lcc}
\hline & \multicolumn{2}{c}{ Correlation coefficient } \\
\cline { 2 - 3 } Eye & Initial & Final \\
\hline Right & 0.687 & 0.844 \\
& $\mathrm{p}<0.0020$ & $\mathrm{p}<0.0002$ \\
Left & 0.625 & 0.809 \\
& $\mathrm{p}<0.0048$ & $\mathrm{p}<0.0003$ \\
\hline
\end{tabular}




\section{CS G FOLLOW UP 4.9 yrS RIGHT VISUAL FIELDS OF 102 EYES}

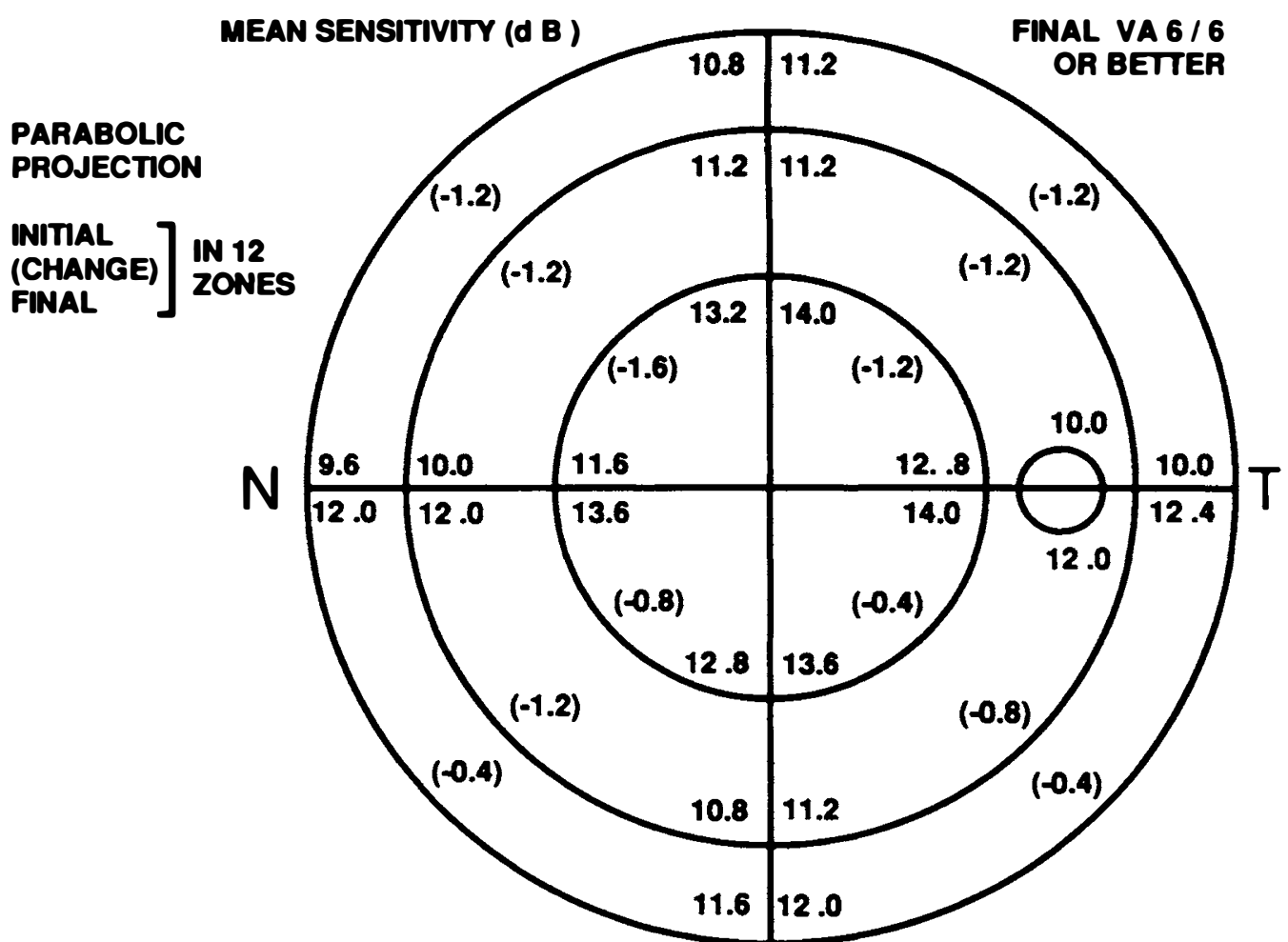

Fig. 8 Chronic simple glaucoma, 102 right eyes with final visual acuity of 6/6 or better. Initial, final and change of mean threshold sensitivity in $d B$ during 5.0 year follow up.

ted for publication ${ }^{1}$ has nevertheless shown (Fig. 11) that the higher the pre-treatment intraocular pressure the worse is the presenting field and in addition (Fig. 12) that those with a higher mean treated intraocular pressure tended to lose field faster than those controlled to a lower level. It must be emphasised that although these relationships were highly significant statistically the correlation coefficients, particularly for the effect of treatment, were fairly low.

Quigley and his colleagues ${ }^{12}$ have shown that extensive optic nerve damage can predate 'detectable abnormality in standard perimetry' and this, together with the findings recorded here and the observations of many other investigators indicate the need for a reappraisal of management policy both for patients with 'confirmed ocular hypertension' as previously defined and for those with areas of minor field depression even though the intraocular pressures are within the statistically 'normal' range.

The objective is to bridge what we regard as the 'Quigley Gap', the period in which there is no demonstrable perimetric defect, yet other visual function tests may reveal optic nerve fibre destruction, which doubtless would be confirmed if the pathological anatomy was accessible.

This is especially important because a previous analysis of the same data-base indicated that the leading risk factor for field loss in treated chronic glaucoma was the degree of initial loss before treatment commenced. ${ }^{13}$

\section{Conclusions and their relevance to Chronic} Glaucoma Management

(a) The distribution of visual field impairment in ocular hypertension correlated closely with that in chronic simple glaucoma. The data support the view that there is no essential 


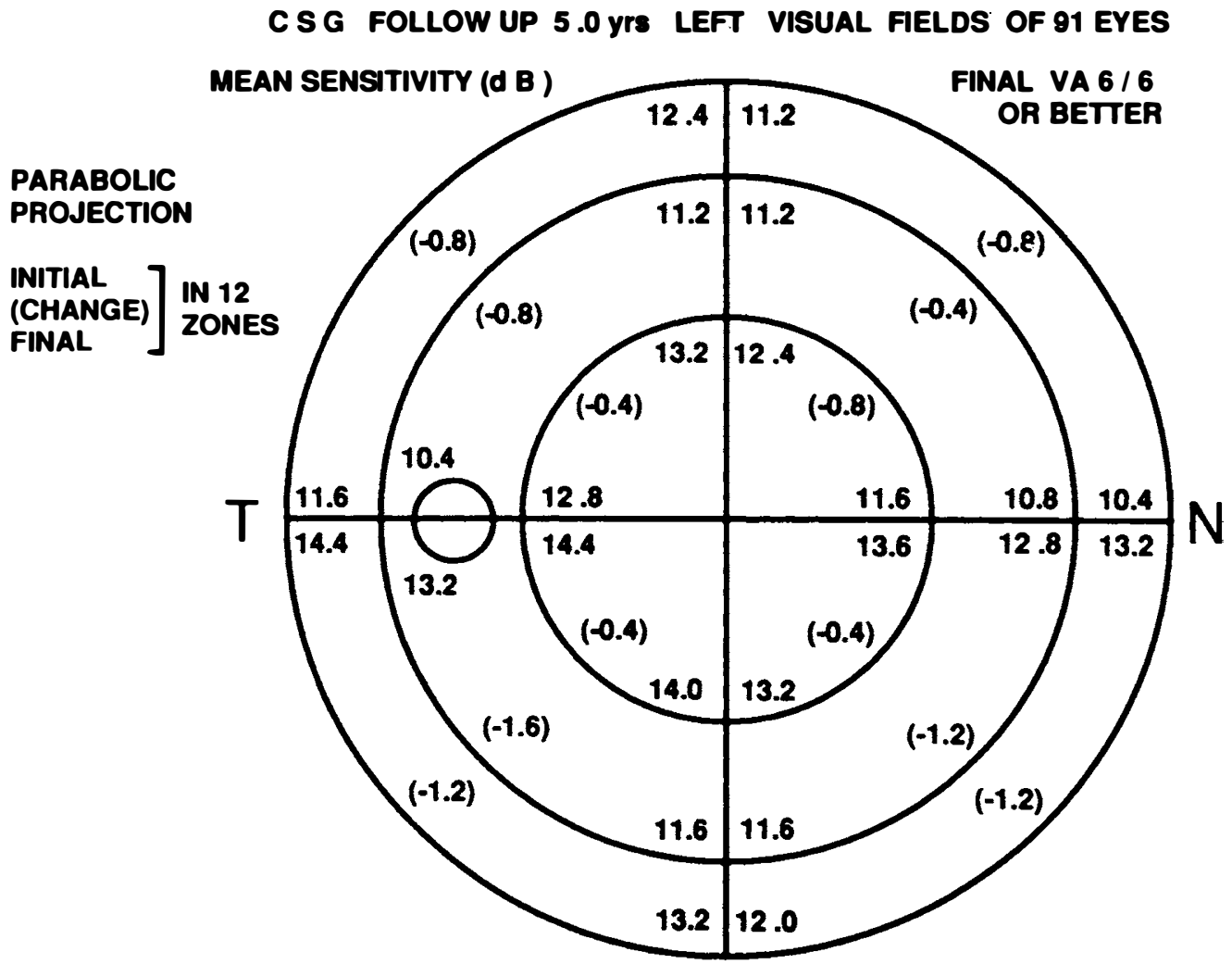

Fig. 9 Chronic simple glaucoma, 91 left eyes with final visual acuity of $6 / 6$ or better. Initial, final and change of mean threshold sensitivity in $d B$ during 5.0 year follow up.

difference between ocular hypertension and chronic simple glaucoma each of which forms part of the primary open angle glaucoma complex.

(b) In the group studied, the outstanding mean visual field change detected in both chronic simple glaucoma and ocular hypertension was a fairly uniform depression of mean sensitivity throughout the field together with a lesser variable extra depression in the arcuate areas. Even mild, apparently nonspecific, visual field depression may well indicate the presence of the primary open angle glaucoma complex and especially if the diurnal phasing reveals peaks above about $18 \mathrm{~mm} \mathrm{Hg}$.

(c) Such patients (and ideally all patients suspected of the primary open angle glaucoma complex) can only be monitored effectively by the regular use of a standardised perimeter

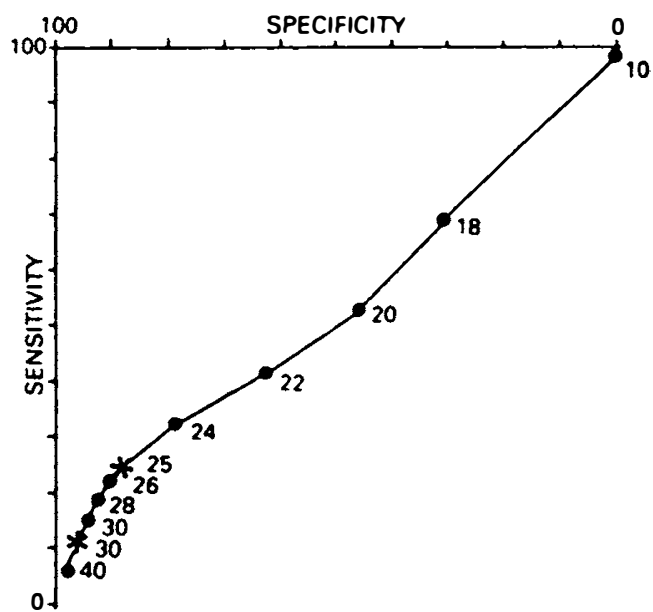

Fig. 10 Decision curve (receiver operating characteristics). Sensitivity and specificity at different levels of intraocular pressure in $\mathrm{mm} \mathrm{Hg}$ as an indicator of visual field loss (KCH data). 


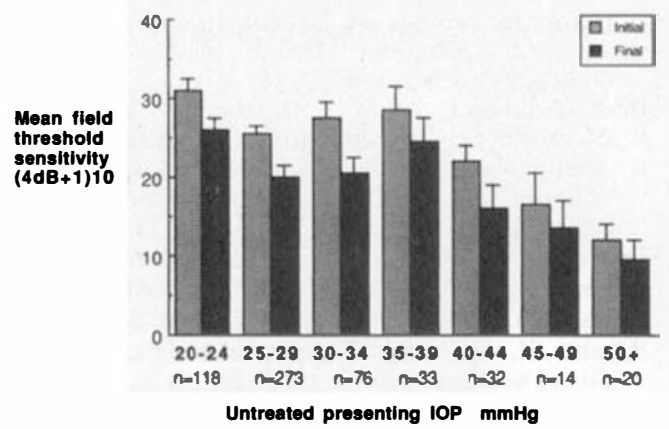

Fig. 11 Chronic simple glaucoma, 566 worse eyes. Initial and final mean threshold sensitivity of $30^{\circ}$ visual field (visual field coefficient) in units of $(4 \mathrm{~dB}+1) \times 10$ versus untreated presenting intraocular pressure $-m m \mathrm{Hg}$.

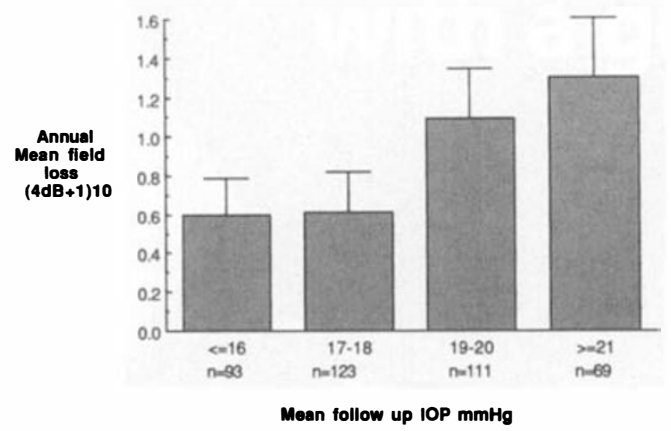

Fig. 12 Chronic simple glaucoma, 396 worse eyes. Annual loss of mean visual field threshold sensitivity (visual field coefficient) in units of $(4 \mathrm{~dB}+1) \times 10$ versus mean follow up intraocular pressure $-\mathrm{mm} \mathrm{Hg}$.

giving numerical threshold values and pupil diameters at a standardised background brightness and ambient lighting, so that existing or progressive depression of general field sensitivity, as well as differential (usually arcuate) depression, can bé detected and measured. The results of other tests of visual function such as contrast sensitivity ${ }^{14,15}$ or blue-yellow colour vision ${ }^{16}$ may well indicate which patients require treatment. The presence of other risk factors such as a family history of chronic glaucoma, high myopia or diabetes would also influence this decision.

(d) While recognising that intraocular pressure is not the only factor in glaucomatous visual field loss, a vast amount of anecdotal experience as well as quantification studies as those mentioned above, suggest that it would be an error to deny either its relevance or the therapeutic value of its reduction. In the future, we shall doubtless have additional means of treating the primary open angle glaucoma complex, but at present if a patient's visual field continues to deteriorate, the clinician now has evidence to justify reducing the peak diurnal intraocular pressure by medical treatment or if necessary surgery, not just to the statistically derived $21 \mathrm{~mm} \mathrm{Hg}$ but to much lower levels.

We wish to thank the Joint Research Committee of King's College Hospital and the Medical Department of M.S.D Chibret for financial support. We gladly acknowledge the valuable technical help of the S.E. Thames Regional Computer Centre and the I.G.A Research Staff for valuable technical help.

The maintenance of the Glaucoma Data Base involves extensive team work by all members of the Department of Opthalmology at King's College Hospital. We are particularly indebted to Mr. Roger Coakes, Dr. Patricia Reynolds, Mrs. Elaine Hammond, Miss, Judith Alexander, Mrs. Sangita Buck, Mrs. Jean Curtis, Mrs. Eileen Cobb and for medical illustrations to Mr. Colin Clements.

\section{References}

${ }^{1}$ Vogel R, Crick RP, Newson RB, Shipley M, Blackmore $\mathrm{H}$, Bulpitt $\mathrm{CJ}$ : The association between intraocular pressure and loss of visual field in chronic simple glaucoma. Br J Ophthalmol (In Press).

${ }^{2}$ Crick RP: Prevention of blindness from glaucoma using the King's College Hospital computerised problem orientated medical record. $\mathrm{Br} J$ Ophthalmol 1975, 59: 236-48.

${ }^{3}$ Aulhorn E: Comparative visual study in patients with primary open angle glaucoma and anterior ischaemic optic neuropathy. Doc Ophthalmol Proc 1980, 22: 3-13.

${ }^{4}$ Phelps CD, Hayreh SS, Montague PR: Visual fields in low tension glaucoma, primary open angle glaucoma and anterior ischaemic optic neuropathy. Doc Ophthalmol Proc 1983, 35: 113-24.

${ }^{5}$ Hollows FC, and Graham PA: The Ferndale glaucoma survey. In: HUNT L B Ed. Glaucoma, Edinburgh: Livingstone, 1966, 24-44.

${ }^{6}$ Bebie H: Compatibility of different Octopus models with respect to normal values. In: Proc. Third Octopus User's Meeting, Niagara Falls, N.Y. 1984, 41-43.

${ }^{7}$ Krakau CET: Discussion of paper by Leydhecker W. Is glaucoma therapy useless? In: Krieglstein GK and Leydhecker W Eds. Glaucoma update II. Springer-Verlag, Berlin. 1983, 100-101.

${ }^{8}$ Sponsel WE, Dallas NL, Burbridge L: Visual field survival: the response to timolol therapy in open angle glaucoma. Br J Opthalmol 1983, 220-7.

${ }^{9}$ Bengtsson B: Aspects of the epidemiology of chronic 
glaucoma. Acta Ophthalmol (Suppl), Copenhagen 1981, 146: 1-48.

${ }^{10}$ Crick RP and Daubs JG: Epidemiological aids to clinical decision making in primary open angle glaucoma. Int. Ophthalmol. 1980, 3: 37-41.

${ }^{11}$ Daubs JG and Crick RP: Blindness prevention through control of ocular hypertension: an epidemiological assessment. Int Ophthalmol 1980, 3: 43-9.

${ }^{12}$ Quigley JA, Addicks EM, Green WR: Optic nerve damage in human glaucoma. Arch Ophthalmol 1982, 100: 135-46.

${ }^{13}$ Wilson R, Walker AM, Dueker DK, Crick RP: Risk factors for progressive glaucomatous visual field loss: A computer based analysis. Arch Ophthalmol 1982, 100: 737-41.

${ }^{14}$ Bodis-Wallner I, Atkin A, Nitzberg S, Mylin L: Psychophysical investigation of abnormalities in contrast sensitivity in glaucoma. In: Leydhecker W and Krieglstein G (Eds) Ocular Hypertension Heidelberg, Kaden Verlag, 1983, 69-77.

${ }^{15}$ Daubs J, Crick R, Reynolds P: The Arden gratings test as a risk indicator for field loss among glaucoma patients. Glaucoma 1984, 6: 248-54.

${ }^{16}$ Alvarez SL and Mills KB: Spectral and flicker sensitivity in ocular hypertension and glaucoma. Res Clin Forums 1985, 7: 83-94. 